\title{
Influence of Bottom Bubbling Condition on Metal Emulsion Formation in Lead-Salt System
}

\author{
Duk-Yong SONG, ${ }^{1)}$ Nobuhiro MARUOKA, ${ }^{2)}$ Toshiaki MAEYAMA, ${ }^{3)}$ Hiroyuki SHIBATA ${ }^{2)}$ \\ and Shin-ya KITAMURA ${ }^{21}$
}

1) Student, Graduate School of Engineering, Tohoku University, 2-1-1 Katahira, Aoba-ku, Sendai 980-8577 Japan. E-mail: ssongdy@mail.tagen.tohoku.ac.jp 2) Institute of Multidisciplinary Research for Advanced Materials, Tohoku University, 2-1-1 Katahira, Aoba-ku, Sendai 980-8577 Japan. $\quad 3)$ Formerly Student, Graduate School of Engineering, Tohoku University. Now at NHK Spring Co. Ltd., 3-10 Fukuura, Kanazawa-ku, Yokohama 236-0004 Japan.

(Received on May 6, 2010; accepted on July 20, 2010)

\begin{abstract}
In the steelmaking process, the reaction rate can be enhanced by increasing the interfacial area and an effective method is to emulsify the metal into the slag phase. This phenomenon is called as metal emulsion. An experimental method for investigating the formation of a metal emulsion was established using the $\mathrm{Pb}$ and $\mathrm{KCl}-\mathrm{LiCl}-\mathrm{NaCl}$ system, and the influence of the bottom bubbling condition on the formation of the metal emulsions was clarified. More than 1000 metal droplets were observed in $1 \mathrm{~g}$ of molten salt. The total weight and total surface area of the metal droplets increased with bubbling time and reached a steady state. Both values increased with gas flow rate until $300-500 \mathrm{~mL} / \mathrm{min}$, and subsequently both values gradually decreased and the local maximums were observed. Two modes of droplet formation were observed by high-speed camera; mode $A$ in which a bubble dome with a metal film formed first and metal droplets formed when the bubble became detached from the interface, and mode B in which a metal column formed after the bubble become detached from the interface. The frequency of droplet formation in mode A showed the local maximum behavior at a gas flow rate of $300-500 \mathrm{~mL} / \mathrm{min}$
\end{abstract}

KEY WORDS: metal emulsion; bottom gas bubbling; metal film; bubble rupture; interfacial area; formation rate; sedimentation rate.

\section{Introduction}

In the steelmaking process, the increase in the reaction efficiency (i.e., dephosphorization, desulfurization, etc.) is important since it contributes not only to the yield and productivity of steel but also to energy consumption and environmental problems. For example, the amount of slag and heat loss can be reduced by increasing the reaction efficiency and reaction rate during the process. Generally, the reaction rate between the slag phase and the metal phase is controlled by mass transfer between both phases. Therefore, the reaction rate can be enhanced by increasing the 1) interfacial area, 2) mass transfer coefficient, and 3) equilibrium distribution ratio of impurity between molten slag and steel. The last two parameters have been studied extensively; however, the first one has not received much attention. An effective method to increase the interfacial area is to emulsify the slag into the metal phase or to emulsify the metal into the slag phase. The former and the latter are called as "Slag emulsion" and "Metal emulsion", respectively. ${ }^{1-4)}$ Although slag emulsion is sometimes employed in the steelmaking industry, i.e., hot metal pretreatment by mechanical stirring and by flux injection, the slag particles in the metal phase are not stable and the residence time in the metal phase is not so long. ${ }^{5)}$ On the other hand, the metal particles in the slag phase are stable, and the residence time in the slag phase can be controlled by a change in slag viscosity. ${ }^{5)}$ It is well known that many metal droplets are emulsified in the basic oxygen furnace (BOF) slag, and the impurity content in the metal droplets is very low compared with that in bulk. $\left.{ }^{6}\right)$ Metal droplets in BOF are considered to be formed by the energy of top blowing gas or that of CO gas generation at the interface. ${ }^{7)}$ In the ladle metallurgical process, a metal emulsion has to be formed by bottom bubbling gas. In this condition, it has been found that the metal emulsion was formed by the gas bubbles, surrounded by metal film, which rise into the slag phase. Depending on the surface tension of the metal and slag, two mechanisms of metal droplet formation have been proposed. ${ }^{4)}$ To evaluate the amount of metal droplets suspended in the slag phase, Lin and Guthrie have conducted experiments using oil and water with the addition of the $\mathrm{ZnCl}_{2}$ system. $\left.{ }^{4}\right)$ They have clarified that as the bubbling gas flow rate increases, the droplet formation rate also increases and have proposed an empirical equation as a function of viscosity, density, bubble size and gas flow rate. Poggi et al. have carried out experiments using a lead and molten salt system. ${ }^{9)}$ In this system, as molten salt can be dissolved by water, the suspended metal droplets can be extracted. They observed many very fine lead droplets and also an increase 
of the overall concentration of entrapped $\mathrm{Pb}$ as the bubbling gas flow rate increased. The formation of fine metal droplets is influenced by the behavior of gas bubbles passing through the slag and metal interface. It has been found that the formation mechanism of metal emulsion changed depending on the surface and interfacial tensions. ${ }^{10)}$ Han and Holappa ${ }^{11)}$ have observed the droplet formation behavior in a molten steel and slag system by using X-ray imaging equipment. They found two mechanisms of the droplet formation, i.e., jet entrainment and film entrainment. Reiter and Schwerdtfeger ${ }^{12)}$ have observed such behavior using a cold model system including mercury as a metal phase and found the formation of a column between the bubble and the metal phase.

Nevertheless, the optimum condition for effective formation of the metal emulsion is still far from clear. To simulate the contribution of metal emulsion to the reaction kinetics and to develop a technology to increase the reaction interfacial area by using metal emulsion, quantitative evaluation of metal emulsion behavior is imperative. In this study, to solve this problem, lead and molten salt were used to simulate molten metal and slag, respectively. An attempt was made to clarify the influence of the bottom bubbling conditions on the formation of metal emulsions.

\section{Experimental Methods}

Figure 1 shows a schematic diagram of the experimental apparatus. The $\mathrm{KCl}-\mathrm{LiCl}-\mathrm{NaCl}$ system was employed as molten salt has the following properties: it does not react with metal, it is water soluble and it has a low melting point. A Pyrex glass container of $60 \mathrm{~mm}$ in diameter and $180 \mathrm{~mm}$ in height was used. The height of the lead and molten salt phases was 60 and $70 \mathrm{~mm}$, respectively. The gas injection tube was heated up to the temperature of the furnace by laying it along the outside of the container. The diameter of the gas nozzle was $1 \mathrm{~mm}$. On the basis of the results of the preliminary experiment, $\mathrm{KCl}-\mathrm{NaCl}-\mathrm{LiCl}$ salt $(\mathrm{KCl}: \mathrm{LiCl}: \mathrm{NaCl}=50: 42.1: 7.9$ mass\%) was used in this experiment, and its melting point being about $628 \mathrm{~K}^{15)}$ First, about $300 \mathrm{~g}$ of salt mixed with high purity powder reagents was set in an electric resistance furnace and heated up to $723 \mathrm{~K}$. After salt had melted, about $1900 \mathrm{~g}$ of lead tablets with a purity of 99.99 mass $\%$ were placed in the molten salt bath and melted. After the lead had melted, $\mathrm{Ar}-3 \% \mathrm{H}_{2}$ gas which was passed through a drying device to remove moisture was injected into the melt by a gas nozzle. This time was set as the start of the experiment. After the start of the experiment, bubbling was continued for about $10 \mathrm{~min}$, and during this period, approximately $1 \mathrm{~g}$ of molten salt was sampled at 2 or 3 min intervals. After the cessation of bubbling, molten salt was sampled at 2 or 3 min intervals for $10 \mathrm{~min}$. The samples were quenched by $\mathrm{He}$ gas. The samples were taken at about $35 \mathrm{~mm}$ at a certain height from the interface and at the center line of container. The bubbling nozzle was set about $8 \mathrm{~mm}$ from the bottom and about $7 \mathrm{~mm}$ from the center of the container.

The salt used in this study was water soluble; therefore, the metal particles could be separated from the sample by dissolving it in water. To avoid the formation of $\mathrm{PbClOH}$ precipitates resulting from lengthy contact with water, a

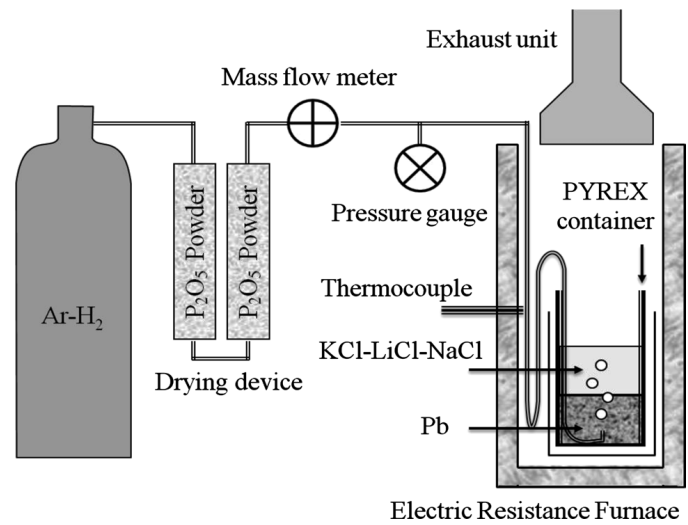

Fig. 1. Schematic diagram of the experimental apparatus to investigate metal emulsion formation by bottom gas bubbling.

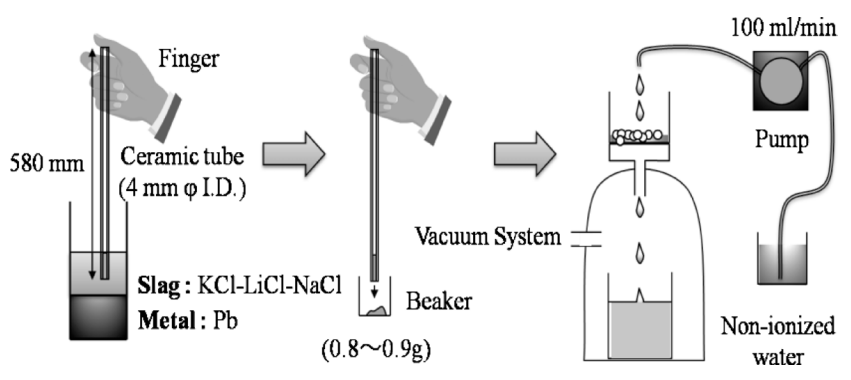

Fig. 2. Schematic diagrams of sampling procedure and vacuum filtering system to extract metal droplets from salt.

vacuum filtering system was applied (Fig. 2). In this method, the obtained sample was placed on the filter, ionexchanged water was dripped slowly onto the sample, and the solution was removed immediately by using the vacuum filtering system. By this procedure, lead particles could be obtained without the formation of $\mathrm{PbClOH} .{ }^{1)}$ Polycarbonate membrane filters with pore sizes of $0.8 \mu \mathrm{m}$ and $8 \mu \mathrm{m}$ were used to filter out the lead particles. The obtained particles were analyzed using a digital microscope.

To observe droplet formation behavior at the interface, the electric resistance furnace was divided into two parts in the vertical direction and a slit about $35 \mathrm{~mm}$ in width was made. From this open slit, the behavior of bubbles and droplets at interface was recorded using a high-speed camera (Casio EX-F1). The speed of the camera was 1200 frames per second and it enabled images to be captured for about $20 \mathrm{~s}$.

\section{Results}

Figure 3 shows the lead droplets on the membrane filter with the pore size of $0.8 \mu \mathrm{m}$. The number of droplets obtained on the filter was counted, and the diameter of each droplet was measured by using a digital microscope. Since there was an extremely large number of droplets on the filter with the pore size of the $0.8 \mu \mathrm{m}$ compared with $8 \mu \mathrm{m}$ filter, only 1000 droplets were measured. Figure 4 shows the size distribution of the metal droplets under the condition of $100 \mathrm{~mL} / \mathrm{min}$ gas flow rate by using the membrane filter with the pore size of $0.8 \mu \mathrm{m}$. As the diameter decreased, the number of droplets increased. The total surface area, $S_{\text {total }}$, and total weight, $W_{\text {total }}$, of droplets in the salt were calcu- 


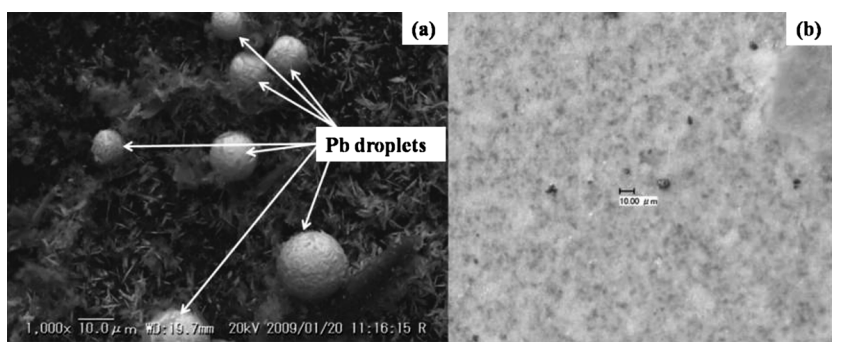

Fig. 3. Micrographs of metal droplets on the membrane filter of $0.8 \mu \mathrm{m}$ in diameter using (a) SEM, (b) digital microscope.

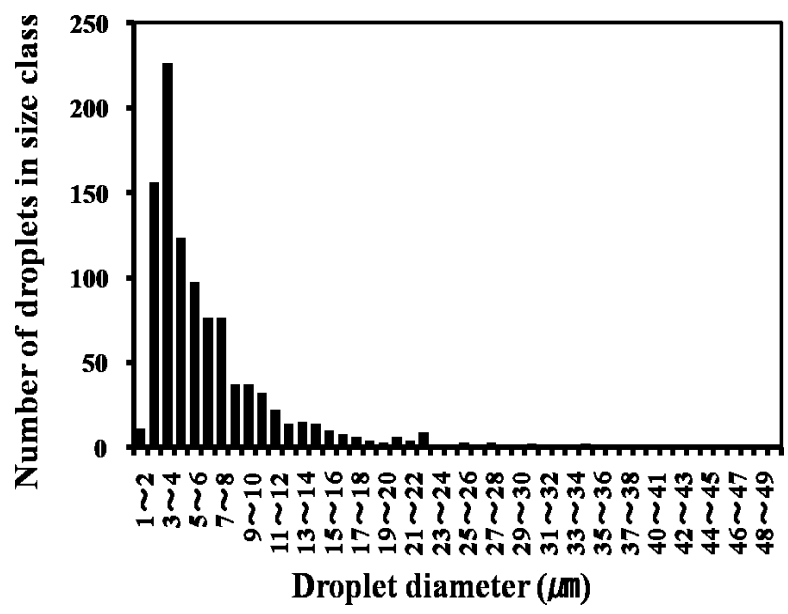

Fig. 4. Size distribution of metal droplets at gas flow rate of $100 \mathrm{~mL} / \mathrm{min}$.

lated using Eqs. (1) and (2), respectively:

$$
\begin{gathered}
S_{\text {total }}=4 \pi r_{1}^{2}+4 \pi r_{2}^{2}+\Lambda+4 \pi r_{n}^{2}=4 \pi \sum_{k=1}^{n} r_{k}^{2} \ldots \ldots . .(1) \\
W_{\text {total }}=\frac{4 \pi r_{1}^{3} \rho}{3}+\frac{4 \pi r_{2}^{3} \rho}{3}+\Lambda+\frac{4 \pi r_{n}^{3} \rho}{3}=\frac{4 \pi \rho}{3} \sum_{k=1}^{n} r_{k}^{3}
\end{gathered}
$$

where $r$ is the radius of a droplet $(\mathrm{m}), \rho$ is the density of lead $\left(\mathrm{kg} / \mathrm{m}^{3}\right)$ and $n$ is the number of droplets. The peak size distribution was $3 \mu \mathrm{m}$ in diameter and the number of droplets over $8 \mu \mathrm{m}$ in diameter accounted for only $22 \%$ of the total. On the other hand, the total surface area and total weight of the droplets over $8 \mu \mathrm{m}$ in diameter accounted for 75 and $92 \%$ of the total, respectively. This result indicates that separation by using the filter with the pore size of $8 \mu \mathrm{m}$ is sufficient to evaluate the emulsion on the basis of weight and surface area, although many droplets below $8 \mu \mathrm{m}$ existed. Therefore, in the following, the emulsion formation behavior was evaluated by the results obtained by using the filter with the pore size of $8 \mu \mathrm{m}$.

Figure 5 shows the change in $S_{\text {total }}$ and $W_{\text {total }}$ with time after the start of bubbling. As shown in this figure, at a low gas flow rate, $W_{\text {total }}$ and $S_{\text {total }}$ gradually increased with time and had very little change after about $5 \mathrm{~min}$. At a high gas flow rate, neither value changed much during the experimental time from $1 \mathrm{~min}$ after the start of bubbling. The time necessary to reach steady state became shorter when the gas flow rate increased. Therefore, it can be considered that
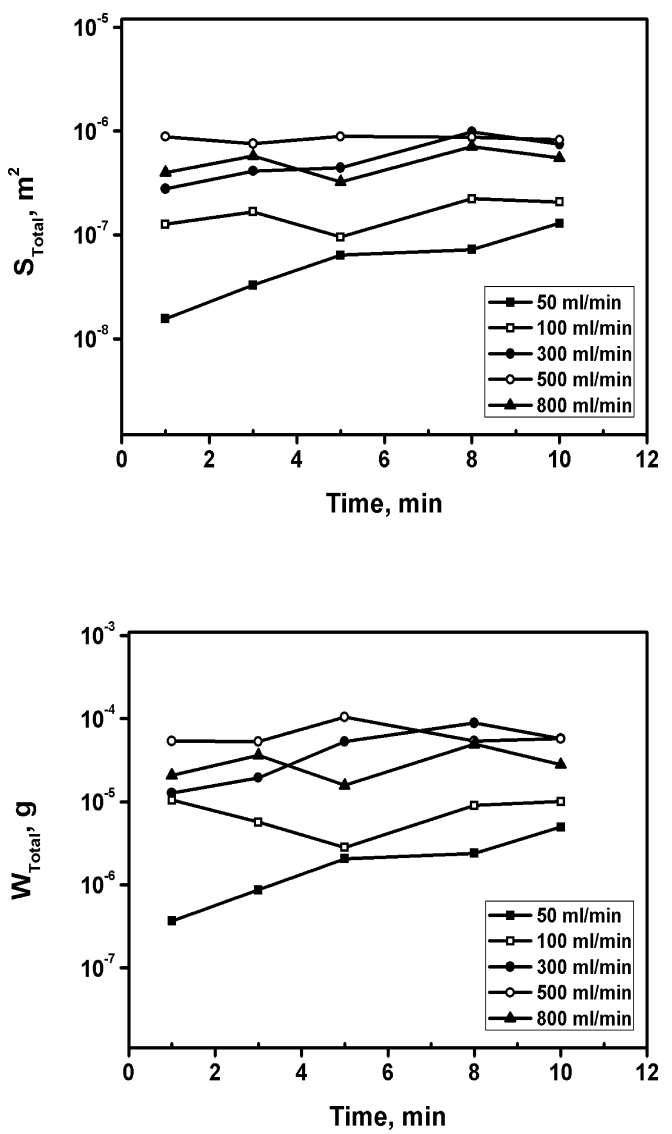

Fig. 5. Influence of gas flow rate on the total surface area and total weight of metal droplets emulsified into the salt phase during bubbling.

the accumulation rate reaches steady state at $8 \mathrm{~min}$ after the start of bubbling. Figure 6 shows the relationship of $S_{\text {total }}$ and $W_{\text {total }}$, to the gas flow rate which was sampled at $10 \mathrm{~min}$ after the start of bubbling. Both values increased with gas flow rate until it reached $300-500 \mathrm{~mL} / \mathrm{min}$ and after that, both values gradually decreased and the local maximums were observed. These results indicate that a higher gas flow rate is not always effective for forming metal emulsion.

The average diameter of droplets, $d_{\text {ave }}$, and the standard deviation of the size distribution $(\sigma)$ were statistically calculated assuming log-normal distribution analysis, and the maximum size of the droplet, $d_{\max }$, was estimated by Eq. (3).

$$
\log d_{\max }=\log d_{\text {ave }}+3 \sigma
$$

Figure 7 shows the change of the average and the maximum diameters against the experimental time. The average and the maximum diameters showed large values for the high gas flow rate condition. The change with time of both values was not clear, although in some cases, they seemed to gradually increase with time. Both values at $10 \mathrm{~min}$ after the start of bubbling are summarized in Fig. 8. Similar to the results shown in Fig. 6, the maximum diameter shows the largest value at a gas flow rate of about $500 \mathrm{~mL} / \mathrm{min}$. The maximum diameter of droplets was approximately $71 \mu \mathrm{m}$ at the gas flow rate of $500 \mathrm{~mL} / \mathrm{min}$.

Figure 9 shows the change in $W_{\text {total }}$ and $S_{\text {total }}$ with time after the cessation of bubbling. In every case, both values decreased by about $1 / 5$ to $1 / 10$ for $1 \mathrm{~min}$ after the cessation 

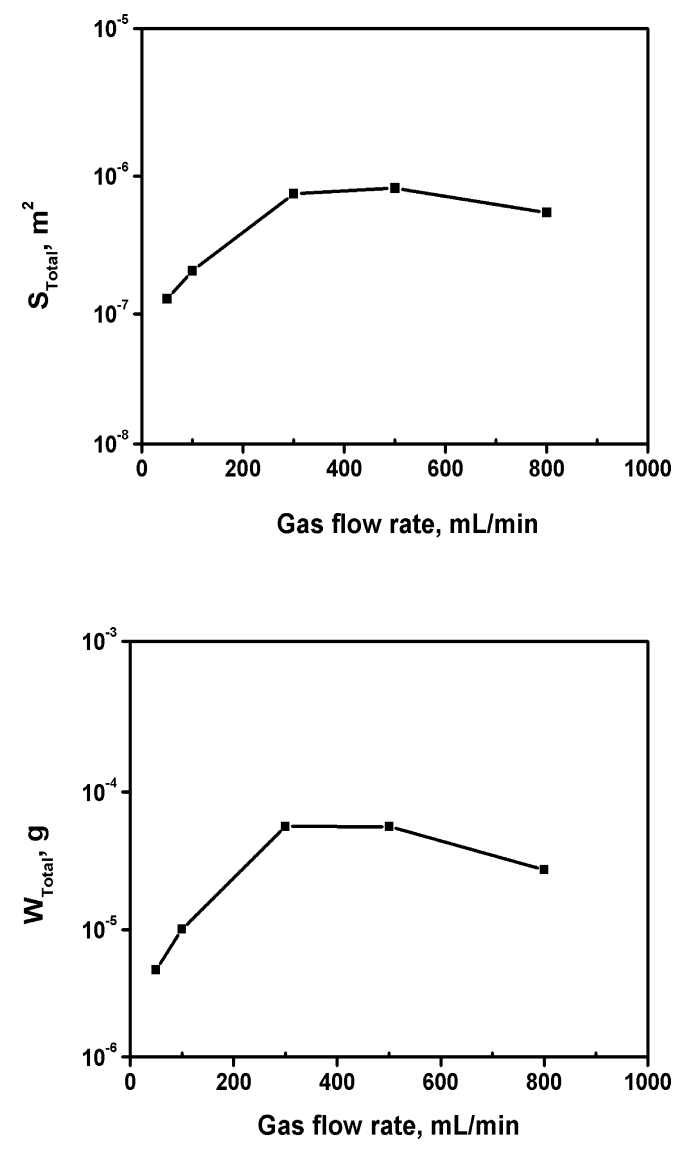

Fig. 6. Influence of gas flow rate on the surface area and weight of metal droplets emulsified into the salt phase sampled $10 \mathrm{~min}$ after the start of bubbling.
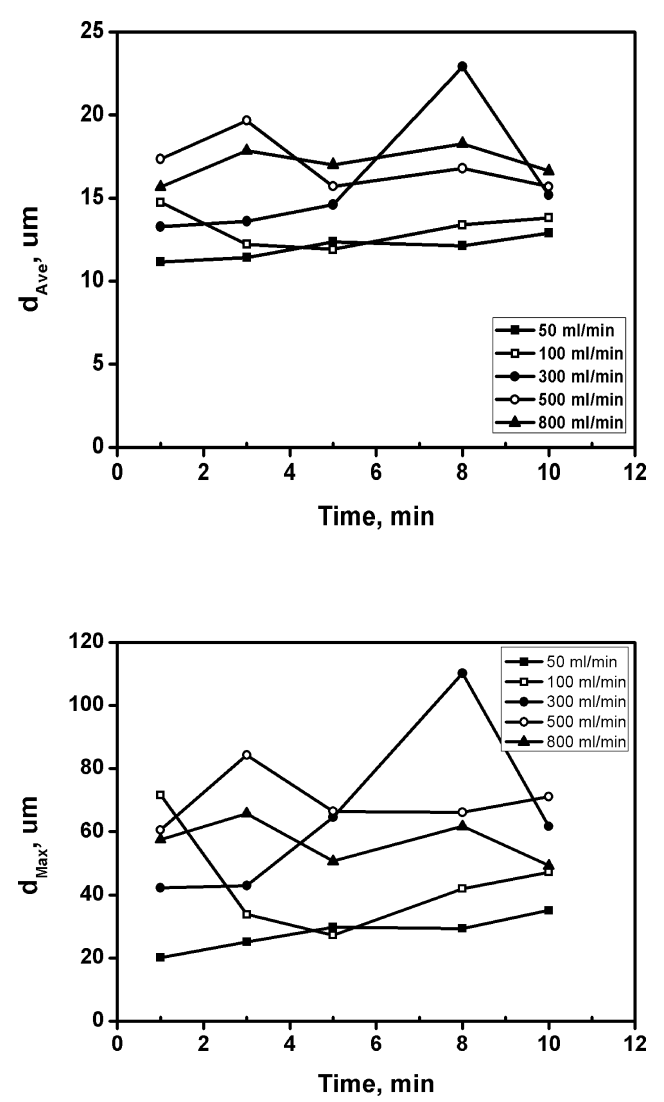

Fig. 7. Influence of gas flow rate on the average and maximum diameter of metal droplets emulsified into the salt phase during bubbling.

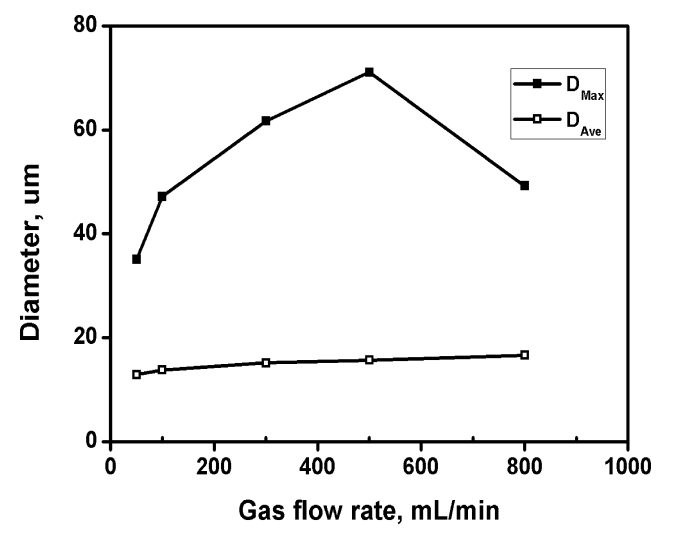

Fig. 8. Variation of metal droplet size at each gas flow rate.
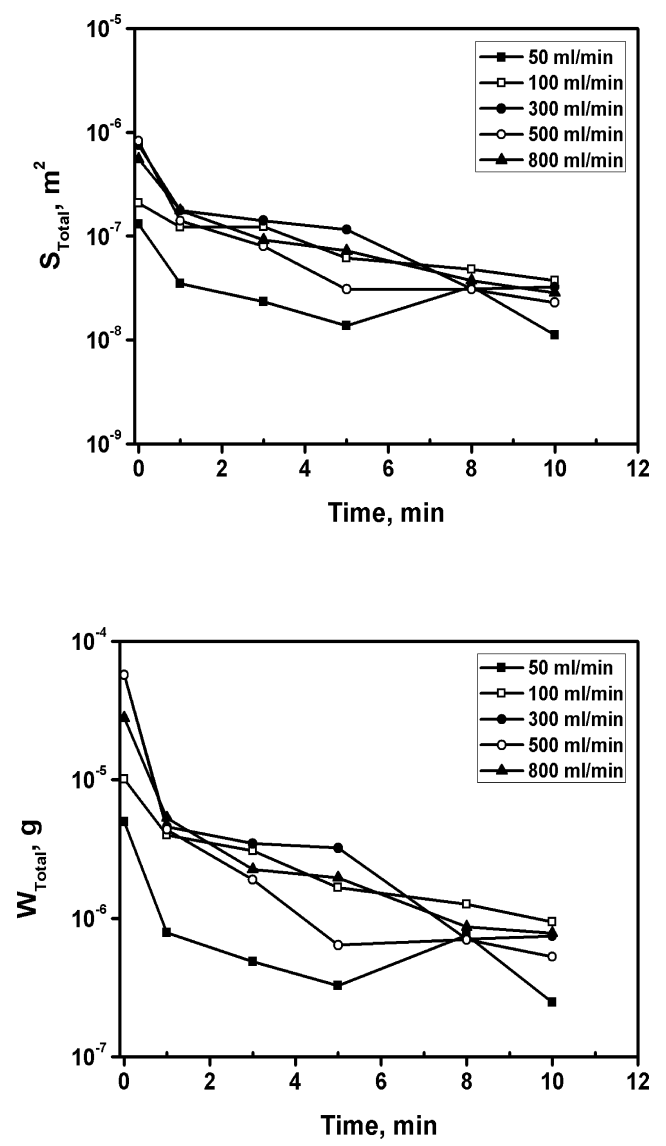

Fig. 9. Influence of gas flow rate on the total surface area and total weight of metal droplets emulsified into the salt phase after the cessation of bubbling.

of bubbling. In addition, after the cessation of bubbling, $d_{\text {ave }}$ and $d_{\max }$ decreased rapidly and reached the same values independent of the gas flow rate during bubbling, as shown in Fig. 10. Figure 11 shows the change of $W_{\text {total }}$ and $d_{\max }$ values during and after the bubbling at each gas flow rate. From Fig. 9, the decreased rate of $W_{\text {total }}$ at the experimental time was calculated by the Eq. (4).

$$
\left(d W_{\text {total }} / d t\right)^{i j}=\left(W_{\text {total }}^{i}-W_{\text {total }}^{j}\right) /\left(t^{j}-t^{i}\right)
$$

where $W_{\text {total }}^{i}$ and $W_{\text {total }}^{j}$ indicate the total weight $(\mathrm{g})$ of the particles in sample $i$ and $j$, respectively, and $t^{i}$ and $t^{j}$ indicate the time (min) of samples $i$ and $j$, respectively. Figure 12 shows the dependence of $\left(d W_{\text {total }} / d t\right)^{i j}$ on $W_{\text {total }}^{i}$ and a good relation is found. 

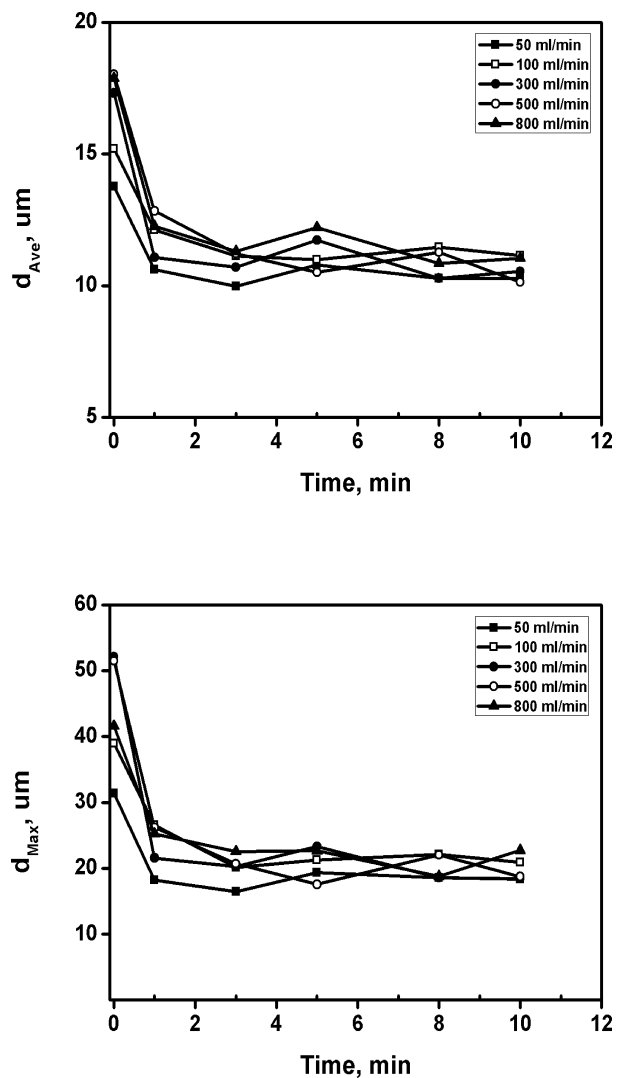

Fig. 10. Influence of gas flow rate on the average and maximum values of metal droplet size emulsified into the salt phase after the cessation of bubbling.
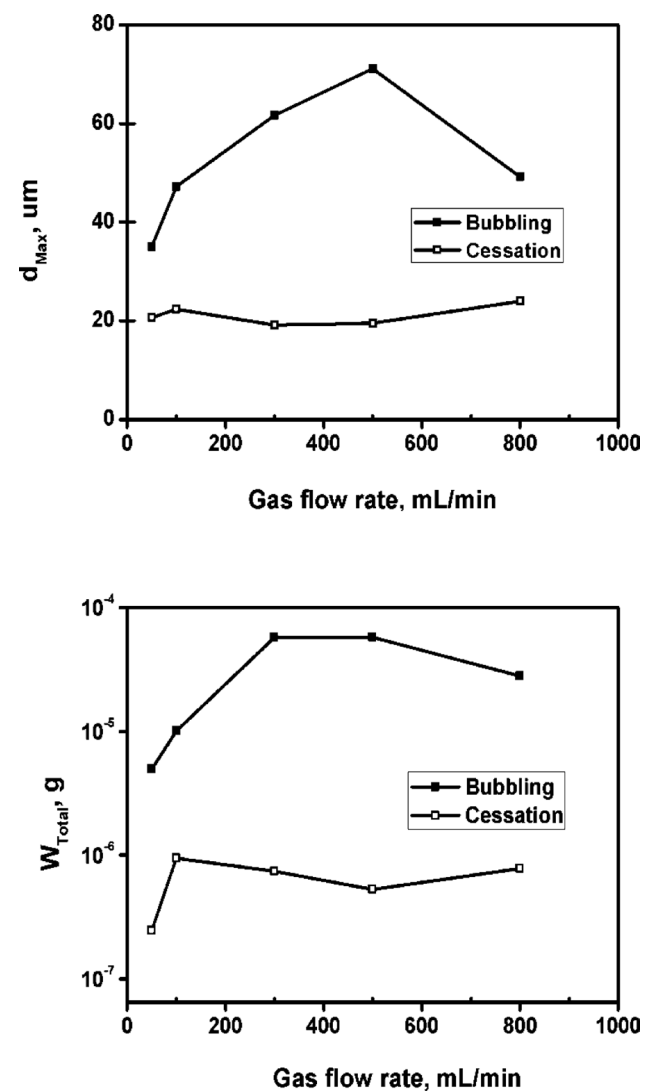

Fig. 11. Comparison of the total weight and maximum diameter of metal droplets at steady state after the start of bubbling and after the cessation of bubbling for each gas flow rate.

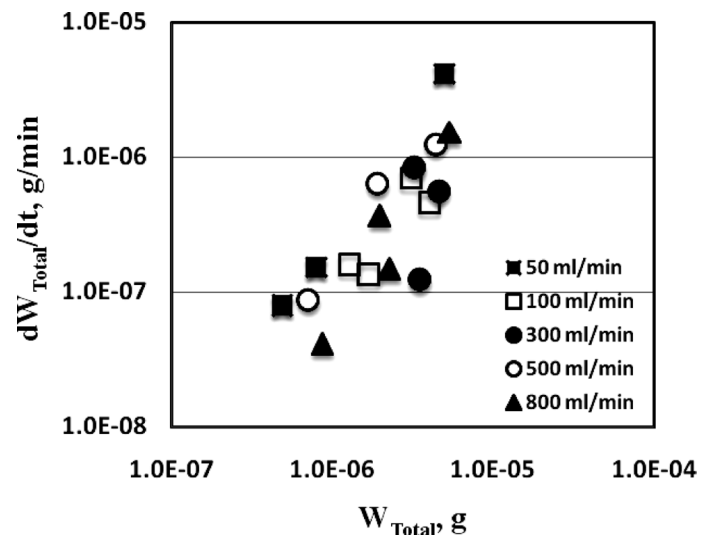

Fig. 12. Relationship between the decreasing rate of lead droplets after the cessation of bubbling and the total weight of lead droplets.

(a)

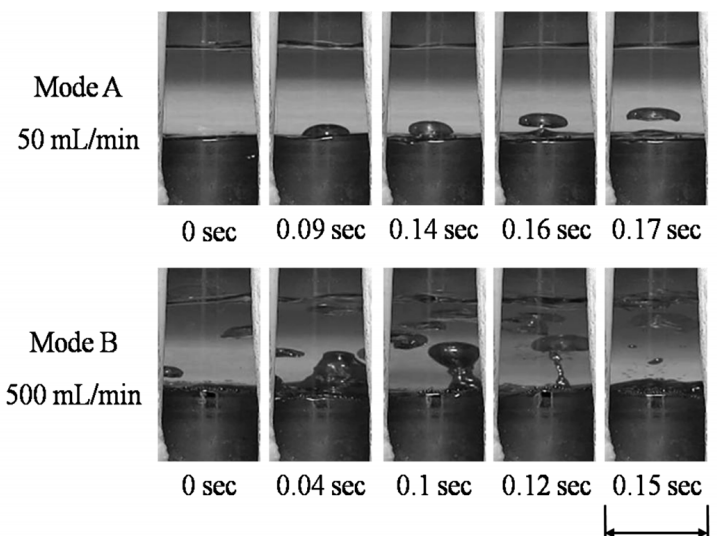

(b)

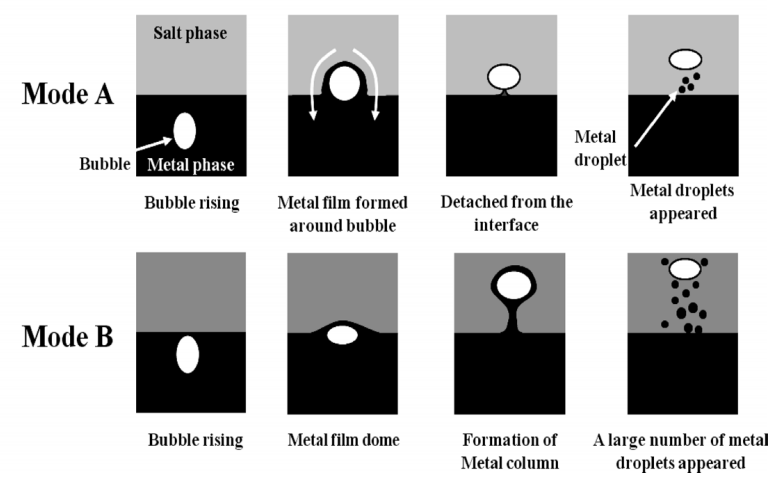

Fig. 13. Behavior of metal droplet formation observed by highspeed camera, (a) photos and (b) schematic diagrams of droplet formation sequences.

Figure 13 shows typical droplet formation behavior at each gas flow rate. Under the low gas flow rate, a bubble dome with a metal film was formed first and after that, metal droplets formed when the bubble become detached from the interface (mode " $A$ "). When the gas flow rate increased, after the bubble become detached from the interface, a metal column was formed between the bubble and the interface and a large number of metal droplets appeared (mode "B"). In this case, metal droplets (or small bubbles with metal film) can be observed at the interface. Similar phenomena were reported by many researchers ${ }^{10-14)}$ either in slag/iron system or in several experimental models. Figure 14 shows the change in the frequency of the bubble de- 


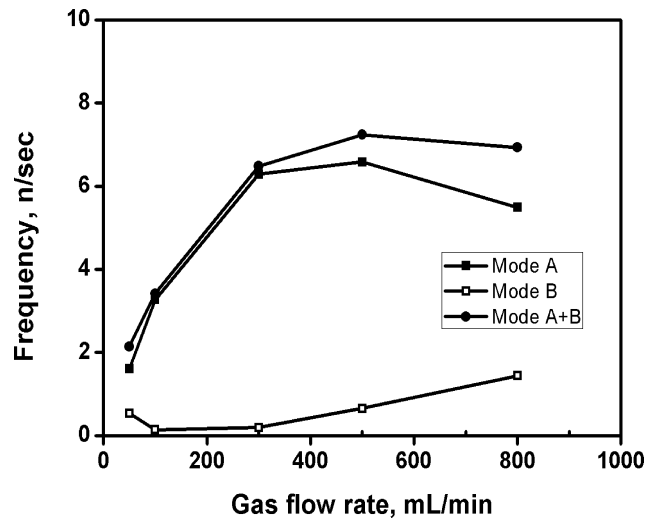

Fig. 14. Relationship between the droplet formation frequency of each mode and gas flow rate.

tachment at each gas flow rate. It is clear that as the gas flow rate increased, the frequency of the " $\mathrm{A}$ " mode increased and reached a maximum value at the gas flow rate of about $300-500 \mathrm{~mL} / \mathrm{min}$, and subsequently, it gradually decreased and the local maximums were observed. On the other hand, the frequency of the "B" mode was observable when the gas flow rate increased more than $300 \mathrm{~mL} / \mathrm{min}$.

\section{Discussion}

The observed weight of droplets is the difference between the formation rate $\left(V_{\mathrm{f}}\right)$ and the sedimentation rate $\left(V_{\mathrm{s}}\right)$. The formation rate can be estimated by Eq. (5) because the formation rate of droplets is not influenced by the weight of droplets in the salt phase. The constant " $c$ " will depend on the gas flow rate.

$$
V_{\mathrm{f}}=d W_{\text {form }} / d t=c
$$

The sedimentation rate can be estimated by Eq. (6) because it mainly depends on the weight of the particles existing in the salt bath, as shown in Fig. 15.

$$
V_{\mathrm{s}}=-d W_{\text {sedim }} / d t=c^{\prime} \times W_{\text {total }}(t)^{n}
$$

The accumulated metal droplets can be calculated by Eq. (7).

$$
W_{\text {total }}=c \times \Delta t-c^{\prime} \times \int W_{\text {total }}(t)^{n} d t
$$

When the formation rate becomes equal to the sedimentation rate which depends on the weight of droplets at that time, the accumulation rate becomes zero and reaches the steady state. If the formation rate is small, as the accumulation rate is slow, the sedimentation rate becomes much slower. Therefore, it takes a long time to reach the steady state, and the accumulated weight of metal droplets becomes small. On the other hand, if the formation rate is large, as the accumulation rate is high, the sedimentation rate increases rapidly. Therefore, it takes a short time to reach the steady state, and the accumulated weight of metal droplets becomes large. This assumption is summarized in Fig. 15 schematically.

In Figs. 6 and 9, the $W_{\text {total }}, S_{\text {total }}$ and $d_{\text {max }}$, the local maximum values were observed as a function of the gas flow rate. It is known that the droplet formation mechanism changes with the gas flow rate even though the physical

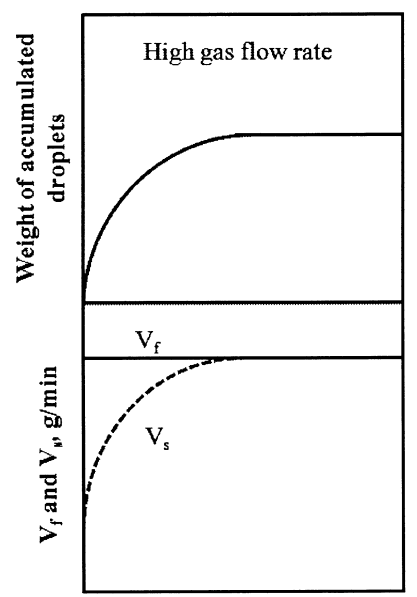

Time, $\min$

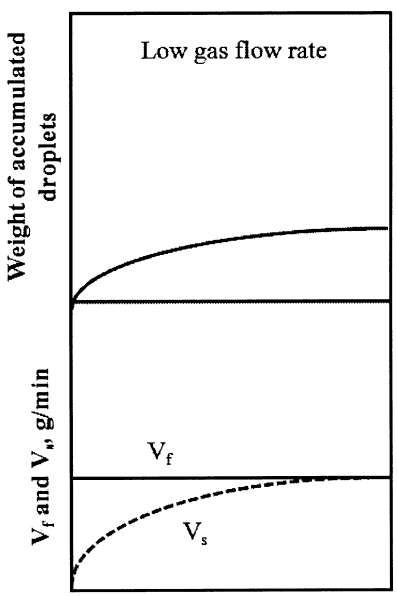

Time, $\min$
Fig. 15. Schematic of the accumulation mechanism of droplets under high and low gas flow rate conditions.

properties of the bath are the same. As shown in Fig. 14, the frequency of droplet formation in mode A showed the local maximum behavior at a gas flow rate of 300-500 $\mathrm{mL} / \mathrm{min}$, and subsequently the frequency in mode B increased. Observation of the fine droplets extracted from the samples by the vacuum filtering system was impossible due to the limited resolution of the high-speed camera. Therefore, the influence of the frequency and mode of the droplet formation on the size distribution is not clear. Nevertheless, it can be considered that the change in the formation mode would have an influence on the optimum gas flow rate for the formation of a metal emulsion.

The behavior of metal emulsion formation in the bottom bubbling condition is primarily influenced by the surface tension, viscosity and the density difference between molten metal and slag phases. Therefore, to apply the metal emulsion formation in the industrial process, it is necessary to evaluate the control factors of the metal emulsion formation.

\section{Conclusions}

An experimental method for investigating the formation of a metal emulsion was established using a lead and salt system, and the influence of the bottom bubbling condition on the formation of metal emulsions was clarified.

The conclusions of our investigation can be summarized as follows.

(1) Metal droplets in molten salt were obtained by using a $\mathrm{Pb}$-molten salt $(\mathrm{KCl}-\mathrm{LiCl}-\mathrm{NaCl})$ system and more than 1000 droplets were observed in $1 \mathrm{~g}$ of the molten salt by a digital microscope.

(2) Total weight and total surface area of metal droplets increased with time after the start of bubbling and reached steady state. With increasing gas flow rate, the time required to reach the steady state became short. Both values increased with gas flow rate until $300-500 \mathrm{~mL} / \mathrm{min}$, and subsequently both values gradually decreased and the local maximums were observed. After the cessation of bubbling, the weight and the surface area of the metal droplets decreased rapidly.

(3) The maximum diameters of the droplets showed the 
largest value at a gas flow rate of about $500 \mathrm{~mL} / \mathrm{min}$. The change in time was not clear, although in some cases, it seemed to gradually increase with time.

(4) According to the observation of droplet formation behavior in molten lead and salt system, two modes were observed: mode $\mathrm{A}$ in which a bubble dome with a metal film formed first and metal droplets formed when the bubble became detached from the interface, and mode B in which a metal column formed after the bubble become detached from the interface. The frequency of droplet formation in mode A showed the local maximum behavior at a gas flow rate of $300-500 \mathrm{~mL} / \mathrm{min}$, and subsequently the frequency in mode B increased.

\section{Acknowledgments}

The authors would like to gratefully acknowledge the financial support of the JFE 21st Century Foundation and Global COE Program of Materials Integration, International Center of Education and Research, Tohoku University.

\section{REFERENCES}

1) M. Martin, M. Endueles and M. Diaz: Can. J. Chem. Eng., 82 (2004), 249.

2) M. Iguchi, K. Takahashi, H. Kawabata, K. Sasaki, S. Yokoyama and H. Kiuchi: ISIJ Int., 38 (1998), 1080.

3) Q. L. He and N. Standish: ISIJ Int., 30 (1990), 356.

4) Z. Lin and R. I. L. Guthrie: Metall. Mater. Trans. B, 25B (1994), 855 .

5) N. Maruoka, F. Lazuardi, T. Maeyama, H. Nogami, G. S. Gupta, H. Shibata and S. Kitamura: Proc. of the 3rd Int. Conf. of Process Development in Iron and Steelmaking, SCANMET III, Sweden, Luleå, MEFOS, (2008), 449.

6) R. D. Pehlke, W. F. Porter and R. F. Urban: BOF Steelmaking Vol. 1, Process Technology Division, Iron and Steel Society of the American Institute of Mining, Metallurgical and Petroleum Engineers, NY, USA, (1982), 397.

7) E. T. Turkdogan: Chem. Eng. Sci., 21 (1966), 1133.

8) T. El Gammal, G. Hinds and U. Schoneberg: Steel Res., 4 (1991), 15.

9) D. Poggi, R. Minto and W. G. Davenport: J. Met., 21 (1969), 40.

10) R. Minto and W. G. Davenport: Trans. IMMC, 81 (1972), 36.

11) Z. Han and L. Holappa: ISIJ Int., 43 (2003), 292.

12) G. Reiter and K. Schwerdtfeger: ISIJ Int., 32 (1992), 50.

13) G. Reiter and K. Schwerdtfeger: ISIJ Int., 32 (1992), 57.

14) S. Kobayashi: ISIJ Int., 33 (1993), 577.

15) G. J. Janz: Molten Salts Handbook, Rensselaer Polytechnic Institute Troy, New York, (1967), 36. 